"Control in the system of managerial decisions procedures: a conceptual view"

AUTHORS Khanif Mullakhmetov

ARTICLE INFO

Khanif Mullakhmetov (2016). Control in the system of managerial decisions procedures: a conceptual view. Problems and Perspectives in Management, 14(3-1), 203-215. doi:10.21511/ppm.14(3-1).2016.07

DOI http://dx.doi.org/10.21511/ppm.14(3-1).2016.07

RELEASED ON Tuesday, 06 September 2016

JOURNAL "Problems and Perspectives in Management"

FOUNDER LLC "Consulting Publishing Company "Business Perspectives"

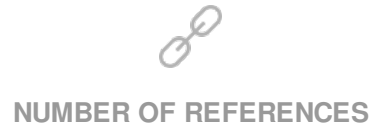

0

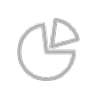

NUMBER OF FIGURES

0

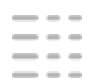

NUMBER OF TABLES

0

(C) The author(s) 2022. This publication is an open access article. 
Khanif Mullakhmetov (Russia)

\title{
Control in the system of managerial decisions procedures: a conceptual view
}

\begin{abstract}
The aim of this study is to investigate the role of control and develop the common approaches to the control in a key area of management - the organization of the process of preparation, adoption and implementation of managerial decisions, which could serve as the basis for creating and maintaining an efficient system of control in organizations and a reference for solving problems in a variety of managerial situations. The structured analysis of the necessary and sufficient set of stages (phases) and the procedures of development, adoption and implementation of managerial decisions that ensure the managerial cycle have allowed the author to evaluate the role and place of the stages and procedures, specify the role of control in the process of management, and the relationship of the control and other managerial procedures. Understanding the characteristics of the relationships and the role of control can be required by the management in order to create a system of control taking into account the specifics of the organization. Analysis of the "managerial" and "executive" decisions allowed the author to identify the ratio of different types of control at their implementation. Interconnection between development technologies, adoption and implementation of managerial decisions and control procedures provides some practical importance for management. The results of the study can be used by management of various organizations to develop common approaches to solving problems in various managerial situations, using the conclusions drawn by the author.
\end{abstract}

Keywords: management, control, managerial decisions, purpose of the managerial decision, problem.

JEL Classification: M19, L29, D80.

\section{Introduction}

Managerial decisions (hereinafter - MD) as a multivalued and multi-faceted category have several interpretations. One of them is based on a "rational behavior" and "viable choice" of the participants in the development and adoption of MD, which have a conscious goal; the second considers the decision as a result of the activities of the organization with an inner potential, structure, technology and culture; the third - as a result of the negotiations between stakeholders (Chudnovskaya, 2007).

In the scientific and popular literature, the development, adoption and organization of the implementation of MD are considered in the broad and narrow sense. For example, Herbert Simon, in his works on the science of decision-making in management, defines a managerial decision as a process comparable with the process of management. Some authors consider managerial decision as a choice from the available alternatives to solve the problem (Meskon et al., 2002; Raizberg et al., 2007).

In our opinion, a broad understanding of the process of development, adoption and implementation of $\mathrm{MD}$, when it is associated with the entire management activity, is the most reasonable in today's operation and development of organizations: after all, in the multifactorial and dynamic environment of modern business with a high level of uncertainty, the choice

(c) Khanif Mullakhmetov, 2016.

Khanif Mullakhmetov, Branch of the Kazan Federal University in Naberezhnye Chelny, Republic of Tatarstan, Russia. between the alternative solutions to the problem that allows to best achieve the organization's goals is just one of the steps in the system of MD procedures.

Competence of the manager is determined, first, by his or her ability to make high-quality MD (adequate to the problem) and, secondly, by his or her ability to organize the implementation of decisions taken (Litvak, 2012). The criterion for the MD adequacy is practice: one-type problems should not repeat in the future operation of the organization in the case of implementation of quality decisions. Solutions are "personal products" of the manager, as he or she makes decisions on problems within his or her competence and independently from cultivated styles, technologies, management tools and methods, development and adoption of MDs, and he or she should be responsible for the results (Mullakhmetov, 2011a).

Responsibility for the operation of the preparation and implementation of decisions is an essential characteristic of the managerial process: "...decision-making, ordering the implementation and the related responsibility are integral and essential features of management and are, therefore, not delegated" (Hahn, 1997).

Implementation of the basic functions of management (planning, organization, motivation and control) is provided through the development, adoption and implementation of MDs in these functional areas. For example, D. Hahn believes that systematic and aimed at future events process of will formation, i.e., the process of development and adoption of MD, can be interpreted as the planning process (Hahn, 1997). MDs 
act as a link between control functions and are referred to communication functions, along with communications, in the modern classification of management functions. Modern classification of management functions involves dividing them into three groups: major or basic (planning, organization, motivation and control), communication (communication, development and adoption of MD) and integrating or operational (management and leadership).
Management is a continuous information and communication process: to solve problems in various functional areas of the organization's activities, the management system generates managerial decisions; quality (accurate, timely and as complete as possible) and relevant (demanded to solve the problem) information is required for the development and adoption of MD. One of the sources of information for the implementation of MD procedures is feedback, supported by control subsystem (Figure 1).

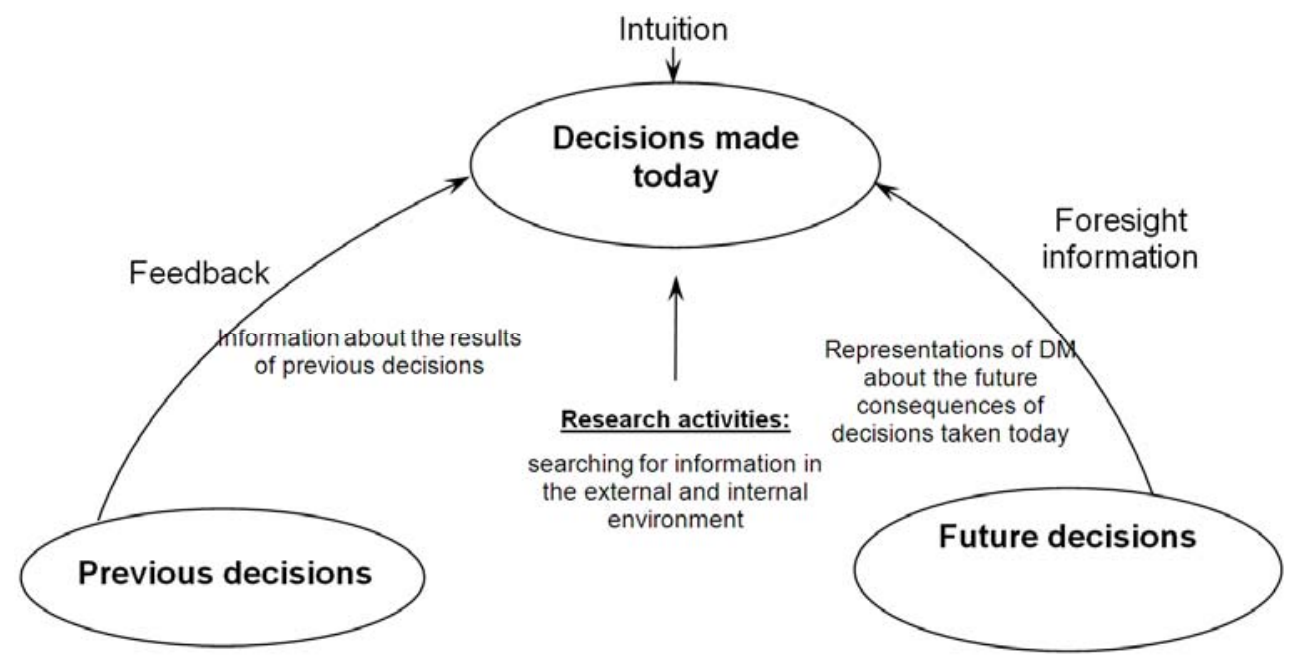

Fig. 1. Information support of preparation and making managerial decision

Perceiving the development, adoption and organization of the MD implementation as a critical component of the management process, let's consider the role of control in this process and create common approaches, which should be the basis for creating and maintaining an efficient system of control in organizations.

We should note that the role of control in the management system has an integrated nature: it is involved in the implementation and evaluates success of both the management process as a whole and individual functions, while providing the management with information at all stages of development, adoption and implementation of MDs using methods of preliminary (anticipatory), current and final control.

\section{Literature review}

Due to legacy of the command-administrative management system assuming the lack of economic independence and, hence, responsibility, the control was considered mainly in the field of accounting and reporting, and was seen in the business environment of Russia as an accounting tool. As a rule, the control is not considered an independent object and subject of study in the works published today either.

Given the absence of dedicated studies on the topic "Control in the system of procedures of managerial decisions", we have to rely on the results of general studies on management and control or studies on the development process, adoption and implementation of managerial decisions in our work.

Traditional foreign textbooks (Mescon et al., 2002; Daft, 2009; Robbins \& Coulter, 2004) contain sections "Making MD" and "Control"; the role of the control in the analysis of decision-making is considered fragmentarily and is reduced to the establishment of feedback as the final stage of the entire process of preparation, adoption and implementation of MD.

Analysis of the process of control by various authors allows to highlight the stages of planning, setting standards, identification of the actual results, comparison, and corrective actions (Table 1).

Table 1. Authors and stages of the process of control they propose

\begin{tabular}{|c|l|c|c|c|c|c|}
\hline \multirow{2}{*}{ No } & \multicolumn{1}{|c|}{ Authors } & \multicolumn{5}{|c|}{ Stages of the process of control (by the content of the operation) } \\
\cline { 3 - 7 } & & Planning & Setting standards & Identification of the actual results & Comparison & Corrective actions \\
\hline \multirow{2}{*}{1} & $\begin{array}{l}\text { M. Mescon, } \\
\text { M. Albert, } \\
\text { F. Khedouri }\end{array}$ & - & + & & + & + \\
\hline
\end{tabular}


Table 1 (cont.). Authors and stages of the process of control they propose

\begin{tabular}{|c|l|c|c|c|c|c|}
\hline \multirow{2}{*}{ No } & \multicolumn{2}{|c|}{ Authors } & \multicolumn{5}{c|}{ Stages of the process of control (by the content of the operation) } \\
\cline { 3 - 7 } & & Planning & Setting standards & Identification of the actual results & Comparison & Corrective actions \\
\hline 2 & $\begin{array}{l}\text { P. Robbins, } \\
\text { M. Coulter }\end{array}$ & - & - & + & + & + \\
\hline 3 & L. Mullinz & + & + & + & + & + \\
\hline 4 & D. Hahn & - & - & + & + & + \\
\hline 5 & R. Daft & + & - & + & + & + \\
\hline 6 & $\begin{array}{l}\text { A.G. Porshnev, } \\
\text { Z.P. Rumyantseva et al. }\end{array}$ & - & + & + & + \\
\hline
\end{tabular}

Source: Mullakhmetov, $2011 \mathrm{~b}$.

In the analysis of stages of control, the authors usually do not link them to the stages of development, adoption and implementation of MD.

We see the process of managerial control as constantly repeating stages:

- identification of the desired (target) state of the object of control;

- identification of the actual state of the object of control;

- comparison of actual and desired states of the object of control by the specified control parameters, detection of deviations; and

- corrective actions that may be directed both at the managerial decisions and their implementation, and at changing the objectives of the organization (Mullakhmetov et al., 2014).

The authors of works on managerial decisions consider control in the process of development, adoption and implementation of $\mathrm{MD}$ or in the context of ensuring the implementation of $\mathrm{MD}$, which is also connected with motivational activities of managers (Smirnov, 2002; Gaponenko, 2008; Fatkhutdinov, 2007), or in the context of quality management (Litvak, 2012; Firsova et al., 2012). The first approach is based on the results of the joint studies of place and role in the control of the management system, the second - on the general terms of quality management.

R.A. Fatkhutdinov, to a certain extent, equates the development, adoption and implementation of MD and process management as a whole and lists the objects of control by the subsystems of the management systems, which include both internal and external factors that influence the operation and development of the organization. Among the environmental factors to be controlled, the author lists the parameters of the macro environment (political, economic, climatic, demographic, scientific and technological, cultural factors), the parameters of corporate micro environment (customers, competitors, distribution system, contact audience) and the parameters of development of the regional infrastructure. The author believes that the rationale of the controlling and controlled subsystems and the implementation of the objective function of management must be controlled by the CEO personally, as the decisions in these areas determine the effectiveness of the management system as a whole (Fatkhutdinov, 2007).

The approaches to quality management underwent transformation in the second half of the XX century: it is insufficient to confine to quality control of the finished product - it is necessary to control all the stages of production and management, i.e., managerial activities including the procedures of development, adoption and implementation of MD should also be object of control. The thesis of the total quality control (TQC) was first formulated by A.V. Feigenbaum, developed in Japan into scientific methods of control and spread to various areas - the service sector, trade, human resources, decision-making, i.e., to the entire management cycle. Deming Cycle being distributed on the entire management process can be represented as follows (Figure 2) (Litvak, 2012).

\begin{tabular}{|l|l|}
\hline $\begin{array}{l}\text { 1. PLAN } \\
\text { Choosing the topic } \\
\text { Defining the goal } \\
\text { Developing the plan of } \\
\text { implementation }\end{array}$ & $\begin{array}{l}\text { 3. CHECK } \\
\text { Checking the result }\end{array}$ \\
\hline $\begin{array}{l}\text { 2. DO } \\
\text { Study of the state of affairs } \\
\text { Development of measures } \\
\text { Implementation of measures }\end{array}$ & $\begin{array}{l}\text { 4. ACTION } \\
\text { Review and correction } \\
\text { Goals of the plan }\end{array}$ \\
\hline
\end{tabular}

Fig. 2. Deming Cycle covering the entire management cycle

According to the PDCA method, presentation of the appropriate level of quality requires the continuous repeating of the following stages:

1. Planning (PLAN): what, when, how, who, and through what should be done (resource provision).

2. Implementation (DO), i.e., the execution of the planned works: study of the state of affairs, development of measures, implementation of measures.

3. Checking (CHECK), i.e., evaluation of the results of the works performed: specification of objectives (expected results), identification of the actual result, correlation (comparison) of the expected and actual results, variance analysis, proposals on possible options for corrective actions, spread of the best practice and educating effect. 
4. Correction (ACTION), i.e., adjustment: the adjustment of plans in the light of results (information) in the checking stage, making necessary changes.

5. In many cases, managers avoid checking and analysis of the results of the works performed, thus, losing the opportunity of continuous improvement. Even in the absence of deviations, there are following options of improvement based on the results of the checking stage:

- the "bar" can be "raised" to reach a new level of the work performance; and

- the performance standards can be set on the basis of the implementation, which will be the basis for future training and control (Deming, 2000).

\section{Methods}

Many authors emphasize that MDs must ensure objectives of the organization: “...the right decision is what largely ensures the objectives of the enterprise" (Shegda, 1998). Or "the goal of the managerial decision is to ensure movement to the objectives of the organization" (Bashkatova, 2008). In this connection, it is necessary to determine the relationship between the concepts "objective of the organization" and "goal of the managerial decision".

The need for MD occurs when the following problem arises: "...the definition of objectives is not yet a formulation of the problem, and there is no need for decisions and actions without it" (Shegda, 1998). The managerial situation is identified as a problem, especially when the desired and actual states of the control object do not match, and the deviation between them creates a significant threat to the achievement of the objectives of the organization. Thus, for example, N.B. Filinov considers that "...the problem requiring managerial decision is understood as a mismatch (gap) between the objectives a decision maker sets or pursues and the actual (projected) state of affairs in the controlled system (object or process)" (Filinov, 2009). Some sources identify a problem as a situation of uncertainty, which creates discomfort for persons in this area of uncertainty.

Goal setting and problem solving are interrelated activities under a single management process: the purpose of the organization in the process of MD development and adoption is shown through the problem; by solving the problem, the management achieves the goals of the organization (Figure 3, Figure 4). In addition, the search for and evaluation of alternative solutions to the problem at the significant changes in the environment could lead to an adjustment of the very purposes of the organization.
The right definition of the problem (adequate to the situation, exact by key factors) becomes extremely important for the effective achievement of the objectives of the organization. The formulation of the problem sets the frameworks of the choice and determines the process of analysis and evaluation of possible solutions. At the same time, characteristics of the person making decision (hereinafter - the decision maker) are very important, as well as his or her ability to adequately reflect the existing objective circumstances and the relationship of the factors forming these circumstances. Incorrect statement of the problem leads to the wrong benchmark. The solution of the wrongly formulated problems leads to waste of resources, negative attitude to the management system, increasing resistance of the personnel to the control over their activities. At the same time, as a rule, the negative effect is much higher than with ineffective solutions of the correctly formulated problems. "The successful decision taken on the basis of clearly defined problems is almost always better than excellent decision made based on the poor definition of the problem" (Hammond et al., 2007).

Summarizing the previous judgments, it can be said that the goal of the managerial decision is always to eliminate the problem, while the problem itself may reflect significant deviations from the desired state of the managed objects in different areas, some aspects, periods of activity, etc., can be linked to persons and situational factors.

In the MD preparation and implementation, it is important to determine the area of a problem to be solved: whether it is in the control area, in the area of influence or outside the area of influence of management (Dettmer, 2013). In the control area, the management manages events and, therefore, the control subsystem realizes the full potential of the control procedures. In the area of influence, for the purpose of effective implementation of the organization's goals, the management interacts with the external environment of the organization, and the need for strategic control increases; outside the area of influence, the most important thing is to identify the key environmental factors that affect the realization of the goals of the organization and monitor changes.

Considering the standard (traditional) management cycle (Figure 3), it is necessary to draw attention to the omission that substantially reduces the effectiveness of management practices. 


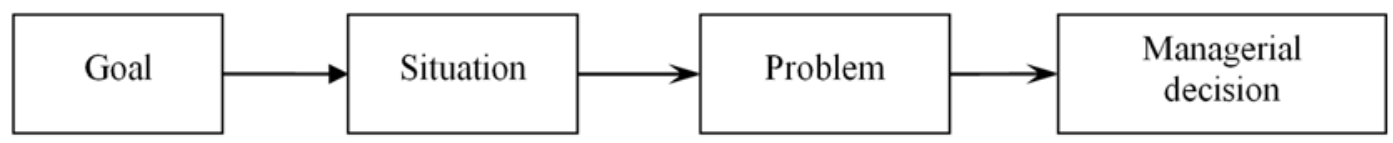

Fig. 3. Traditional management cycle

The presented scheme can be simplistically interpreted as follows: management begins with goal setting (in accordance with the concept of P. Drucker); goals are implemented in individual cases, which can be favorable and unfavorable: when the situation is unfavorable, a problem occurs; to correct the problem (ensure achievement of the goal), a managerial decision is made.

At this approach, implementation of the goal in a situation much more favorable than the one at the formulation of the goal falls outside the scope of management. The favorable situation creates new opportunities to better achieve the goal. To implement the emerged opportunity, it is also necessary to make a managerial decision. Peter Drucker stresses that the solution to the problem only restores the norm, while the results should be a consequence of using the opportunities (Drucker, 1964). This approach provides a broader understanding of the problem: "The dual understanding of the problem: on the one hand, the problem is understood as the mismatch between the actual and desired at the unknown ways of continuing this mismatch; on the other hand, the problem means difference the mismatch between the actual and potential" (Kulagin, 2001). Then, the management cycle will be as follows (Figure 4).

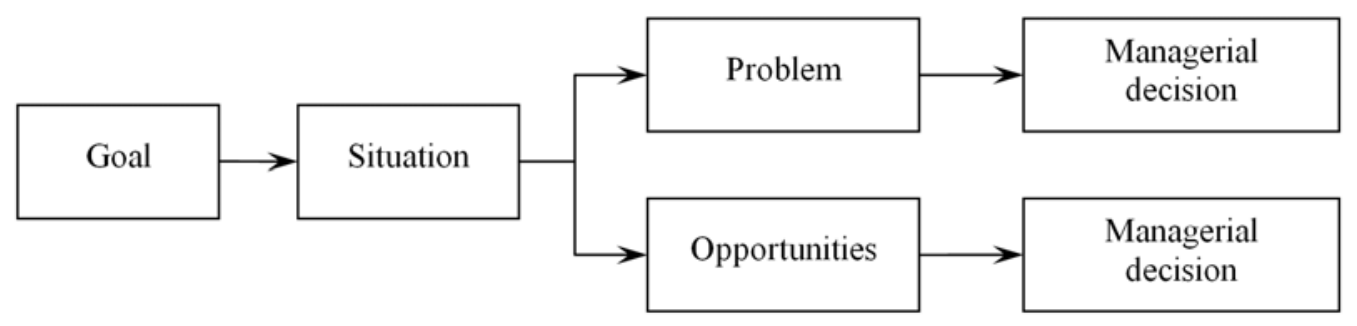

Fig. 4. Management cycle that takes into account the opportunities of the organization's environment

Based on the previous judgments, the goal of the managerial decision may be supplemented: managerial decisions are also made in order to use the identified new opportunities to achieve the organization's objectives in general as effectively as possible.

Structuring of the objective function (for example, by drawing up a tree of objectives) allows to determine the desired state of the objects and management processes by management levels and, thus, creates an opportunity for the organization of the systematic control.

Control, the basic procedure of which is the comparison of the desired and actual states of objects and control processes (Figure 5), by identifying and assessing the deviation between them, provides the management system with information on the problems and opportunities, thereby initiating the adoption of appropriate managerial decisions (Mullakhmetov, 2005). Today, the leading Russian companies replace the traditional control systems with the controlling concept, which is generally understood as information provision of enterprise management focused at the result (Mullakhmetov, 2015). Dietger Hahn considers controlling as a tool for integrated planning and control based on a continuous flow of internal and external information (Hahn, 1997). Peter Horvarth and Roland Gleich believe that controlling is a complex cross-functional management concept, the purpose of which is to coordinate the planning, control and information systems (Horvarth \& Partners, 2005).

The system approach underlying the controlling concept comes from the fact that the causes of deviations (failure to eliminate problems, execute plans and objectives), aside from low-quality MD and their low-quality implementation, may also include significant changes in factors of the organization's environment.

The main principle of Toyota's management urges not to seek for the culprit, but to find the cause for the deviation in the system (Liker, 2014). This approach is also supported by Edwards Deming's statistics: the causes of complaints, defects, faults, omissions and other negative factors in 98 cases out of 100 are systemic factors and only in 2 cases personal factors (Fidelman, 2015). 


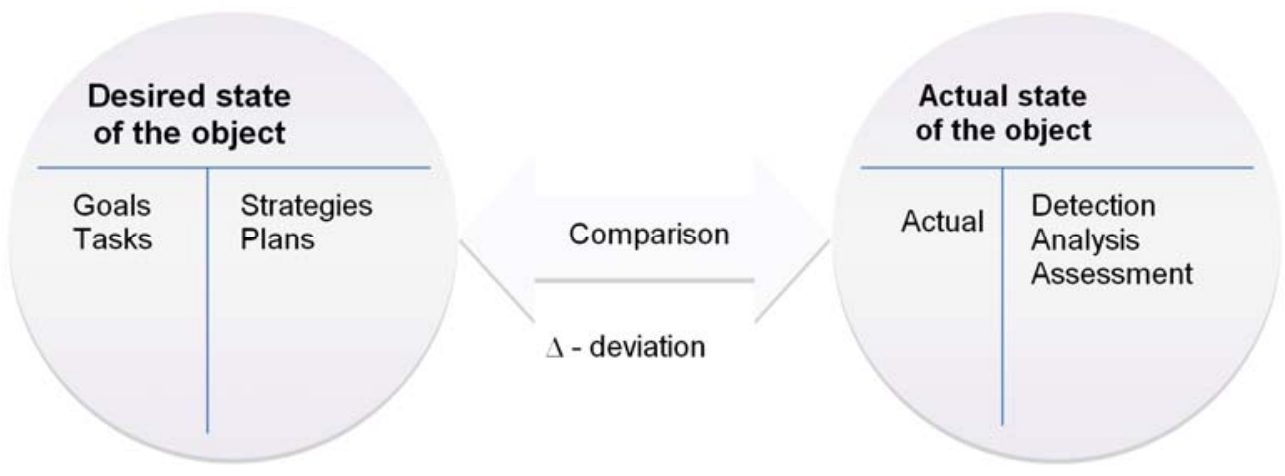

Fig. 5. The simplest model (basic procedure) of control.

\section{Results}

3.1. Control in the preparation, adoption and implementation of managerial decisions. In accordance with the management approach of the representatives of the managerial decision-making school (Herbert Simon, David March), management is a continuous process of seeking for and solving real or potential problems preventing functioning and development of organizations, identification of new opportunities and possibilities. Dietger Hahn considers management as a process of will formation (development and adoption of MD) and will realization (the organization of implementation of the decisions made), as well as problem-solving process in the pursuit of objectives, highlighting the 6 phases (complexes of operations) of this process (Hahn, 1997). We present them in the form of Figure 6.

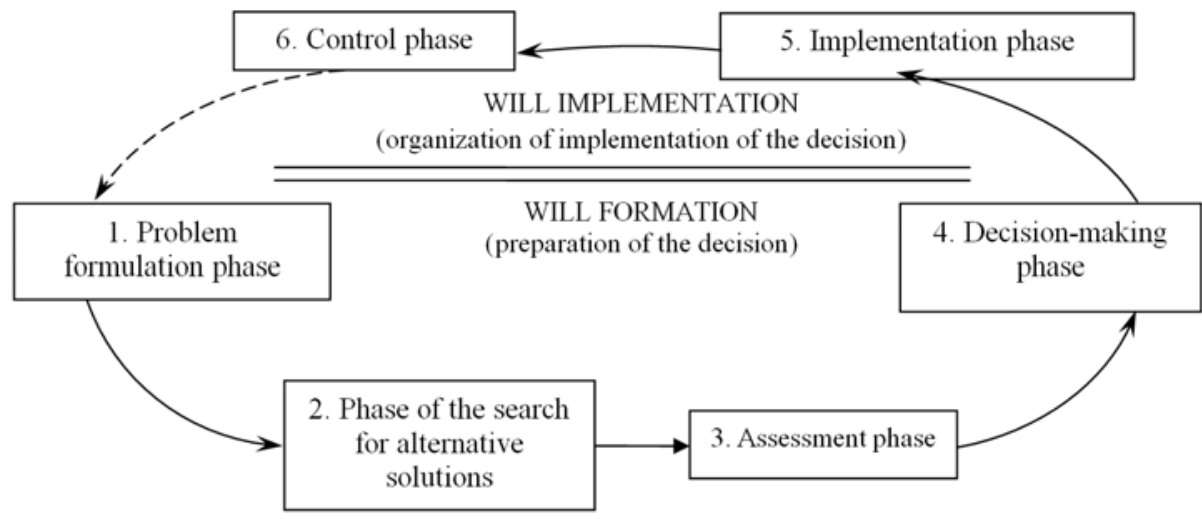

Fig. 6. Control as a process (management cycle)

Let's consider the basic procedures of the process:

1. Problem formulation phase involves the following procedures.

1.1. Identification of the problem by comparing the achieved state (actual) and the desired state (target). By their nature, these actions make up the major control procedure (Figure 5). It is most effectively solved by the concept of management by objectives, which allows to compare the achieved state both with the objectives of individual managers and the goals of higher levels and the entire organization.

1.2. Analysis of the causes of the problem. If we consider the organization as an open system, the causes of the problem can be internal: low-quality management decisions (at management by objectives - goals of the lower levels do not ensure realization of the goal of a higher level), low-quality implementation of managerial decisions; and external: substantial changes in the environment of functioning and development of the organization during the preparation, adoption and implementation of managerial decisions. This circumstance requires constant systematic monitoring of the business environment factors of the organization in the first place: complexity of the market, certainty and stability, degree of diversification, ratio of opportunities and threats in the market, nature of relations with other organizations, as well as factors of indirect effects: economic, political, socio-cultural, demographic, technological, environmental, climatic and geographical.

Thus, the results of this procedure allow us to define the possible directions for solving the problem.

1.3. Identification of the organization's objectives relevant to the problem and goals of individuals related to the problem and its solution. Based on the nature of the problem (whether it refers to a particular object or process, is a system problem or a non-recurrent, causes, consequences, etc.), we identify the 
organization's objectives that are threatened with this problem. We identify the persons whose actions or omissions have created the problem, and those who, in accordance with their competencies, will be involved in solving the problem.

Thus, we determine, firstly, the overall concept in which problem must be solved and, secondly, determine the personnel and their work plan on the problem.

1.4. Identification of constraints and their impact on the organization of the work on the problem. We reveal the basic resources needed to solve the problem, evaluate their compliance with the projected volumes in quality and quantity, determine the effect of deviations by resources on the nature of the organization of the works. As a result, it is possible to determine the resource provision of the solution.

1.5. Clarification and definition of tasks to solve the problem, taking into account the objectives and constraints, allow to make a general plan for the organization of the work on the problem.

The result of the problem formulation phase is the unambiguous definition of the problem to be solved and the conditions under which it must be solved.

2. Phase of the search for alternative solutions involves the following minimum-required procedures.

2.1. Selection of alternatives. Management generates possible solutions to a problem, based on the information received through feedback channels, foresight (intuition) information, studies of the available information and the search for missing data on the various technologies, based on experience and common sense.

2.2. Formation of representations about the influencing factors as a whole and for each of the alternatives. Based on a systematic approach, we determine the main factors of internal and external environment of the organization that influence the problem and implementation of the developed solutions, simulate the strength and nature of their influence in various combinations of factors.

2.3. Based on the results of the previous subparagraph, we choose alternatives subject to detailed study.

The result of the phase is to determine the possible and feasible solutions to the problem in practical terms.

\section{Assessment phase:}

3.1. Assessment of projected impacts of alternatives on achievement of the quantitative and qualitative targets in terms of unambiguous expectations of the future situation in the external environment of the organization - happens infrequently in practice. It is valuable in terms of creating the base model for the next step.
3.2. Assessment of projected impacts of alternatives on achievement of the objectives in the face of uncertainty. Based on the basic model, with the options of changing environmental factors, we determine the degree of achievement of the objectives at the implementation of alternative solutions to the problem.

3.3. Simulating the effects of the implementation of alternatives in terms of possible changes of the objectives, measures and constraints. At significant changes in the environment of functioning and development of the organization, the organization's objectives, measures for their implementation and available constraints may change. At this stage, the adaptability of the alternatives and sufficiency of the available options are assessed.

The result of the assessment phase is ranking of alternatives by the degree of achievement of the major goals of the organization.

\section{Decision-making phase:}

4.1. Comparative analysis and discussion of the assessed alternatives and the results of the simulation with the personnel involved in solving the problem. It is necessary to bring all available information to the personnel, clarify some important points that cause questions and listen to the views of key performers.

4.2. Choosing an alternative that provides the greatest degree of achievement of goals in the current situation, if necessary, making adjustments based on the results of discussion.

The result of the phase is a choice of the alternative to be implemented.

5. Implementation phase involves the detailed development of implementation plan, ordering to start implementation, i.e., inducement to implementation. Implementation of the developed plan should ensure elimination of the problem and, consequently, achievement of the objectives of the organization of the considered levels in the period under review.

6. Control phase involves the following procedures.

6.1. Determination of the results of implementation, i.e., revealing the achieved state (actual).

6.2. Comparison of actual and target results.

6.3. Synthesis and analysis of deviations, identification of the causes of deviations and their consequences, the nature of deviations: attribution (object, process), frequency, etc.

6.4. Generalization and dissemination of good practices. 
6.5. Preparation of proposals for corrective measures, including initiating a new cycle of the problem revision depending on the results of the analysis. In practice, a new cycle of the problem revision is required, firstly, in the case of significant deviations of actual results of implementation of managerial decisions from the target (when the problem is not resolved) and, secondly, in the case of detection of significant deviations from accepted standards of performance and new opportunities in the implementation of previous phases of the management process and problem solutions in general.
The result of the control phase of the management process is to determine the success of the managerial decision-making.

As can be seen from the content analysis of the management process, control acts as a mechanism to ensure continuity and effectiveness of management and supports the orientation of the management system towards the objectives of the organization.

Let's analyze the initial phase of the process - the problem formulation phase - by the content of its basic procedures (operations) - and represent the results of the analysis in the form of Figure 7.

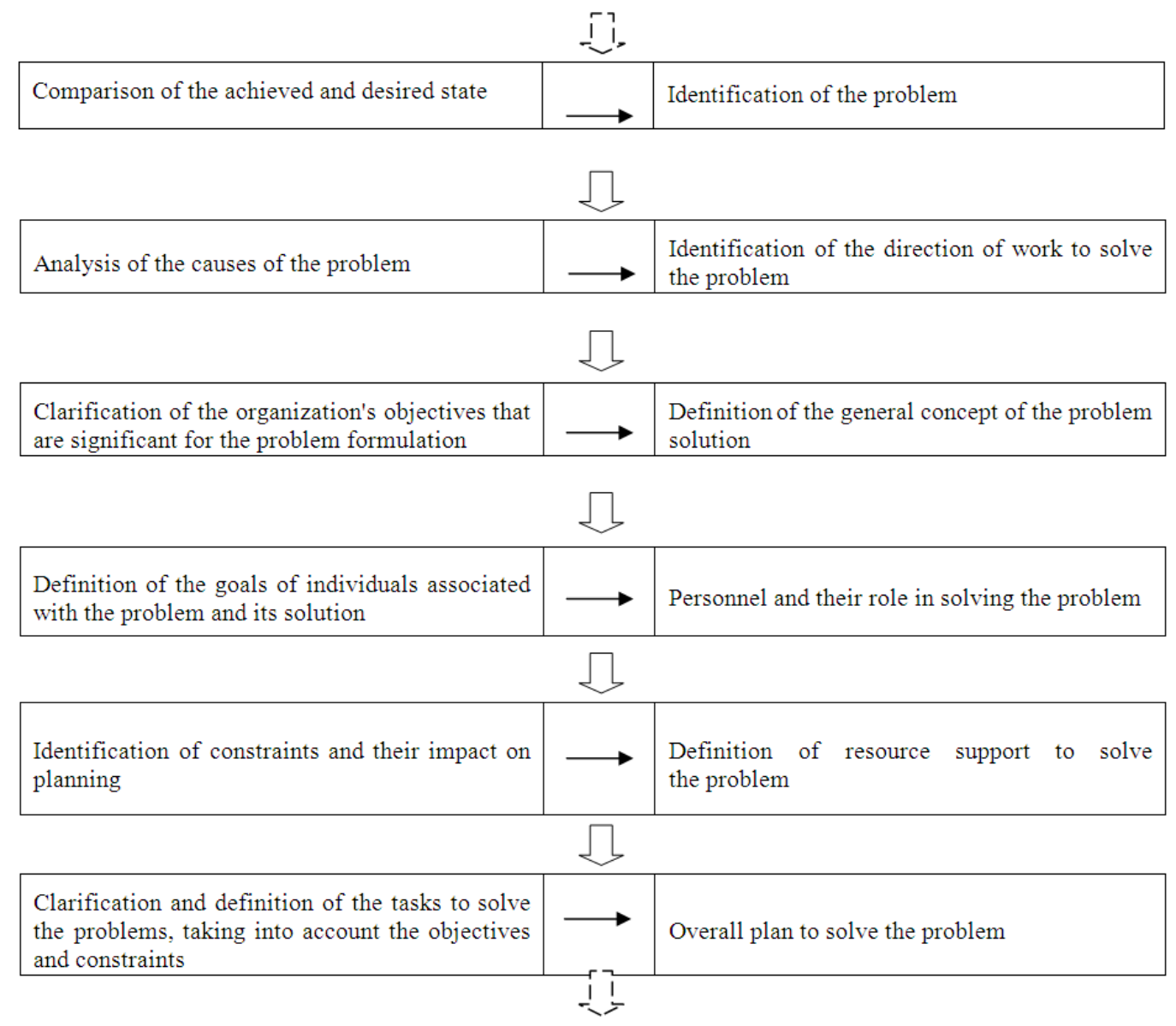

Fig. 7. Content analysis of the problem formulation phase (basic procedures and their goals)

3.2. Control in management process. To determine the place and role of control in management process, it is important to emphasize that, in this phase, the initial procedure is to identify the problem by comparing the achieved (actual) and desired (target) state of the object of control. These actions constitute the essence of the basic procedure for monitoring activities and, therefore, it can be stated that the management as a process (management cycle) begins with the control procedures.

The final phase - control phase - determines the success of the implementation of the administrative decision designed to eliminate the identified problem. It compares actual and target results, analyzes deviations, their consequences and causes, generalizes positive experience; based on the results of the analysis, it may be decided to conduct a new cycle of the problem revision. In addition, new problems to be solved can be identified during the implementation of the management cycle.

Thus, the analysis of the management process by the content of its basic procedures (operations) leads to the conclusion that the management process begins with the provision of information on the problem, useful for management decision-making, on the base of the results of the control procedures, and ends with the control phase, which determines the success of the implementation of the decision, the 
results of which are often the information base for the adoption of new solutions, i.e., information base for the launch of a new management cycle.

Based on such assumptions, we can determine the goal of control in the management system: the goal of control is to improve management efficiency. To achieve this goal, the control solves the following tasks:

- provision of relevant (required for problem solution) and quality (accurate, timely and complete) information about deviations in the processes of operation and development of the organization (about the problem) for the preparation and management decision-making (operational level), planning (tactical level), goal setting (strategic level);

- monitoring of the processes of operation and development of the organization and timely communication on significant deviations from the expected intermediate results (desired state of the management objects) to the management and performance standards;

- comparing the obtained and expected results and identification of deviations; collection, collation and analysis of deviations, their effects and causes, presentation of reasonable options for corrective actions appropriate to the effects of identified deviations (what it led to and how best to eliminate the negative consequences of deviations) and their causes (why this was possible and what it is necessary to do to avoid this in future) to the management.

The first task is solved by the methods of preliminary control, the second - by the current methods, and the third by the final control (Table 2).

Table 2. Types of control and their characteristics

\begin{tabular}{|c|c|c|c|c|c|c|}
\hline № & $\begin{array}{l}\text { Types of } \\
\text { control }\end{array}$ & $\begin{array}{c}\text { Contents of the key control } \\
\text { procedures }\end{array}$ & $\begin{array}{l}\text { Relevance in management } \\
\text { process }\end{array}$ & $\begin{array}{l}\text { Nature of the control } \\
\text { procedures }\end{array}$ & Tasks of the control procedures & Goal \\
\hline 1 & Preliminary & $\begin{array}{l}\text { Monitoring of the managed } \\
\text { (controlled) processes and } \\
\text { objects }\end{array}$ & $\begin{array}{l}\text { During the MD preparation } \\
\text { and adoption (in planning) }\end{array}$ & Constantly & $\begin{array}{l}\text { Presentation of quality (accurate, } \\
\text { timely and complete) and } \\
\text { relevant information about the } \\
\text { problem }\end{array}$ & \multirow{3}{*}{$\begin{array}{l}\text { Improving the } \\
\text { efficiency of } \\
\text { management } \\
\text { activities: to } \\
\text { contribute to best } \\
\text { achieve the goals } \\
\text { of the } \\
\text { organization }\end{array}$} \\
\hline 2 & Current & $\begin{array}{l}\text { Control over the personnel } \\
\text { actions: operations, } \\
\text { milestones and performance } \\
\text { standards }\end{array}$ & $\begin{array}{l}\text { During the MD } \\
\text { implementation }\end{array}$ & Constantly & $\begin{array}{l}\text { Exclusion of significant deviations } \\
\text { from plans and instructions } \\
\text { (performance standards) }\end{array}$ & \\
\hline 3 & Final & $\begin{array}{l}\text { Control over results of } \\
\text { implementation of MD taken }\end{array}$ & $\begin{array}{l}\text { After completion of the MD } \\
\text { implementation }\end{array}$ & $\begin{array}{l}\text { Upon completion of } \\
\text { the management } \\
\text { cycle }\end{array}$ & $\begin{array}{l}\text { Assessment of the success of the } \\
\text { implementation of the decisions } \\
\text { taken. Dissemination of successful } \\
\text { experience. Training effect }\end{array}$ & \\
\hline
\end{tabular}

Analysis of the relationship between the control types and target technologies of development and implementation of MD (DMD technologies) is of particular theoretical and practical interest. E.A. Smirnov identifies the target technologies (TT) and processor technologies (PT) as part of DMD technologies. Target technologies include initiative targeted, programming targeted and regulatory technologies (ITT, PTT and RT, respectively) (Smirnov, 2002). At that, processor technologies are a tool of the targeted technologies and ensure their implementation.

ITT provides for the development by the manager of only the ultimate goal of the task and deadline.

The task does not contain any indications of means and methods of its implementation, thus, providing performers an opportunity to show creativity and initiative. This technology places high demand on the level of professionalism of performers. Therefore, at ITT, the manager should apply preliminary control at the stage of MD development and final control upon completion of works. During the task solving, self-control of the performer is suggested over the deadlines and specific stages and works at structuring of the work by the performer. With this technology, the current control does not apply, since it distorts its content.

PTT provides for the development by the manager of objectives, means and methods of their implementation, as well as deadlines and conditions of the intermediate stages. The content of this technology determines the high level of structure of the tasks and provides for the use of all three types of control. Excluding any of them reduces the possibility of the successful application of PTT.

RT involves the development by the manager of the ultimate goal and strategies to achieve it with the possible limitation of resources. The task indicates the estimated time for execution for performers. Achieving the goal by a given technology can only be guaranteed under strict control, which involves the active use of all three types of control. This technology is used in an innovative and long-term nature of the developments involving a large number of performers. 
As can be seen, ITT involves creative and proactive approach of the performers, PTT is focused on duty performance, RT is provided in a combination of creativity and diligence in different ratios depending on the conditions of technology application (for example, the limitation of resources) with a focus on the duty performance. The control procedures provide the flexibility of management, on the one hand, and compliance with the established order - on the other, depending on the DMD technologies used.

The obtained results are summarized and presented in Table 3 (Mullakhmetov, 2013).

Table 3. Role of control in management process

\begin{tabular}{|c|c|c|}
\hline \multicolumn{2}{|c|}{ Management process (major stages) } & Role of control \\
\hline \multicolumn{2}{|c|}{$\begin{array}{l}\text { Setting goals (strategy of operation and } \\
\text { development) }\end{array}$} & $\begin{array}{l}\text { Introduction of qualitative information about the state of objects and processes in the organization through feedback } \\
\text { channels }\end{array}$ \\
\hline \multicolumn{2}{|c|}{$\begin{array}{l}\text { Development of ways and methods to } \\
\text { achieve objectives (tactical and } \\
\text { operational plans) }\end{array}$} & $\begin{array}{l}\text { Dissemination of successful experience (providing information on successful resolution of similar problems and } \\
\text { challenges in practice) }\end{array}$ \\
\hline \multicolumn{2}{|c|}{$\begin{array}{l}\text { Identification of problems in achieving the } \\
\text { organization's objectives }\end{array}$} & $\begin{array}{l}\text { Monitoring of the achievement of targets by deadlines, resources, results. Presentation of information about } \\
\text { deviations }\end{array}$ \\
\hline \multirow{2}{*}{ 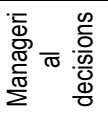 } & Development and adoption & $\begin{array}{l}\text { Providing information on the consequences and causes of deviations. Suggestion of reasonable options of the } \\
\text { corrective action }\end{array}$ \\
\hline & Implementation & Determining the success of the implementation of managerial decisions \\
\hline \multirow{3}{*}{ 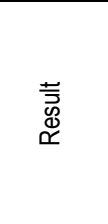 } & $\begin{array}{l}\text { Elimination of the problem } \\
\text { (goal is achieved) }\end{array}$ & Generalization and dissemination of positive experience; training effect \\
\hline & Problem is not eliminated & $\begin{array}{l}\text { Identification of the cause (poor-quality managerial decisions, poor-quality implementation of managerial decisions, } \\
\text { significant changes in the environment); option of the corrective actions }\end{array}$ \\
\hline & New problem is revealed & $\begin{array}{l}\text { Collection, generalization and analysis of deviations in the development, adoption and implementation of managerial } \\
\text { decisions, identification of them as a problem. Provision of information on new problem through feedback channels }\end{array}$ \\
\hline \multicolumn{2}{|c|}{ Adjustment of the organization's objectives } & $\begin{array}{l}\text { Providing information in the system mode about achieving the objectives of the organization, significant deviations } \\
\text { from the objectives, by environmental factors of the functioning and development of the organization }\end{array}$ \\
\hline
\end{tabular}

\section{Discussion}

Famous British management consultants M. Woodcock and D. Francis, depending on the degree of uncertainty of the situation and, accordingly, the risk of failure to reach the desired results, provide 4 levels of decision-making.

Level one: routine - does not require a creative approach, as decisions are made according to established rules (performance standards). The task of the manager is to identify the situation and initiating the action.

Level two: selective - requires a certain initiative and freedom of action, but within the established boundaries. At this, the manager evaluates possible solutions and selects the optimum of the available well-developed alternative.

Level three: adaptation - requires a creative solution that may be completely new. The manager seeks for a new solution to a known problem, based on a set of proven capabilities.

Level four: innovation - the search for solutions to complex problems, where there are many uncertain factors. Extremely important is the correct definition of the problem, not to confuse the cause of deviations with the symptoms (consequence), which often occurs in the analysis of problems in complex systems and requires a deep approach (Woodcock and Francis, 1991).
The higher level of management, the less routine and selective decisions and the more adaptive and innovative solutions; accordingly, the growth of the level of uncertainty makes accents in control activities shift from the operational and management control to strategic control.

Dietger Hahn suggested his own classification of managerial decisions, depending on the level of uncertainty. He divides the decisions into "truly managerial decisions" and "performing decisions" ("operational decisions") upon the implementation of the former. The first group involves making volitional acts adopted in the face of uncertainty, the decisions of the second group are regulated by internal normative documents of the organization (performance standards) and, according to the author, are not truly managerial decisions. He stresses that both types of managerial decisions are prepared and adopted at all levels of management (Hahn, 1997).

So, what is the role of control in the decision-making process of the first and the second group?

The development, adoption and implementation of the "truly" managerial decisions require the whole arsenal of techniques, tools, methods of preliminary, current and final control, which are implemented in all phases of this process. At that, preventive control, designed to reduce the level of uncertainty in the external and internal environment that protects from making decisions inadequate to management problem, becomes very important. 
"Performing decisions" are developed and implemented by the previously developed and tested algorithm; if the algorithm (performance standard) is implemented in a quality manner, and environment of the functioning and development did not change much by the key factors affecting the organization, the management can expect the planned efficiency.

Thus, it requires, firstly, the control over performance standards and, secondly, monitoring of internal and external environments and updating standards adequately to the changes occurred. The first problem is solved in the course of current control, monitoring involves preliminary control, information about the success of the implementation of the decision as always provided by final control. It should be noted that the volumes of the preliminary control procedures are small due to the short cycle of "performing decisions" in time and content of the problems they solve.

As we can see, the role of control in the preparation, adoption and implementation of decisions does not fundamentally depend on the types of MD, there is just a shift in accents: if at the "truly managerial decisions" the volume of the preliminary control increases, "performing decisions" require the system of the current control implementation.

Program of the "performing decisions" does not exclude the need to implement the entire sequence of procedures for the preparation, adoption and implementation of MD, including control, but their substantial part is performed organizationally and requires no intellectual effort. Work on performance standards accelerates management processes, but deprives the control system of flexibility: standards, even if they are revised from time to time or at the significant deviations, may not be optimal for every managerial situation. By ensuring the order, management loses adaptability and, thus, flexibility.

In accordance with the "principle of assessment by results", the criterion for choosing a balance and, therefore, the revision of existing performance standards in the organization of control activities are the results of the implementation of decisions: if decisions are taken in compliance with the standards, executed with high quality, but led to negative results, the standards need to be revised in accordance with the occurred and expected changes in the environment.

In classical management theory, the only correct method of MD adoption was rational model, which presupposed the necessary existence of alternatives to ensure the feasibility and awareness of choice to solve the problem. Although rational model consists of five successive stages (diagnosis of the problem, definition of criteria, formulation of alternatives, assessment of alternatives, choice of alternatives to be implemented), it is impossible to implement them in full in the actual management practice for a variety of restrictions. However, the advantage of the model is transparency of the process and the validity of the adopted decision.

In contrast to the rational model, an intuitive decisionmaking model does not allow to understand the motives behind this decision, because the realization of the problem is followed by a decision-making stage.

It can be assumed that the decision, in this case, was adopted on the basis of intuition and common sense, based on experience, with the possible use of technology archetypes and cognitive modeling. Unconditional achievement of the model is low costs in time and other resources.

The principle of maximization, used in management and involving choosing the best option of all possible, was refuted by the theory of bounded rationality by Herbert Simon. In his works, H. Simon has shown that in the real conditions, managers do not always choose the best solution to the problem, i.e., maximization principle does not work in practice. The reason for this is that the classical economic theory didn't take into account the transaction costs - the costs of collecting and analyzing information on the issue, negotiating, etc. In addition, the time to make a decision usually reduces the resource of time to implement the decision. For these reasons, in practice, the principle of satisfaction is implemented: managers go with the decision option that helps to solve the problem in an acceptable manner, i.e., not the best, but a satisfactory option is implemented (Ryzhenkova, 2011).

The rational model of MD adoption involves control procedures both at the implementation and control phases at the organization of the implementation of adopted MD, and at the previous phases at the preparation and adoption of the decision (as described in the "Results" section). Intuitive model of MD adoption, due to its characteristics, excludes the ability to control the process of decision-making, monitoring of the implementation of the decision is done in the same way as in the rational model.

The MD development and adoption as a process of will formation, as a mechanism for orientation of activities to formation and achievement of the organization's goals, and as a tool for implementing the management functions is a complex, multifaceted system of relations in the organization. The modern science management offers a number of models of decision-making process: SOR-Modell, E. Heinen, H.A. Simon, N. Szuperski, E. Witte, M. Irle, K. Birker, etc. These models include the presence of not only the hierarchical structures (rigid algorithms), but also numerous feedbacks, i.e., control (Dulzon, 2009). Features of the management system, specifics of 
management problems solved, which are also determined by nature of the products (services, works) and technology of its production, ratio of environmental threats and opportunities, internal capacity and corporate culture of the organization, largely determine the particular model of the process.

A proactive approach to problem solving, proposed by American authors John S. Hammond, Ralph L. Keeney, Howard Raiffa (Hammond et al., 2007), is interesting for practice. According to the authors, you can calculate and prepare even the most difficult choice by preliminarily considering the complex of eight elements: problem, objectives, options, implications, compromises that are common to any situation; as well as the unpredictability, willingness to take risks, related decisions that help to make choices in the ever-changing situations.

\section{Conclusion}

Interconnection of MD and control procedures can be traced at all stages of development, adoption and implementation of MD, from identifying the problem at the performance of key control procedure to assessment of success of the implemented decision based on feedback information provided by control. The complexity and diversity of the management process for successful implementation requires an effective system of control, placing a set of demands on it during the stages of this process. Control acts as a mechanism for promoting the achievement of objectives of the organization, providing the management with information on deviations (threats and opportunities), assessing deviations (whether MD is required or not) and offering sound solutions for the identification of deviations as a problem, thus, ensuring the continuity and effectiveness of the management process.

The situation of uncertainty and the associated risk of failure to reach the planned results in developing, adopting and implementing managerial decisions were not considered separately in this work. We believe that this is one of the key problems of the management theory and the ever-present "headache" for managers. In our opinion, the research aimed at striking a balance between control methods aimed to reduce uncertainty through information provision of the procedures of managerial decisions and control methods that ensure the effective implementation of managerial decisions, while respecting the economic principle of organization of control activities (control procedures must not be more expensive than losses they eliminate), will be very promising.

The results of the study can be used by management of the organization to determine the common approaches to solving problems in different managerial situations. A detailed analysis of the content and results of the procedures for the preparation, adoption and implementation of MD by phases, established relationships in the control and other managerial procedures will allow to build the effective system of control: transparent, clear and accepted by all the participants in the economic and administrative processes, to build partnerships between managers and executives, which ultimately helps to reduce the resistance of personnel to systems of management and control, and improve the corporate culture of the organization.

\section{References}

1. Bashkatova, Yu.I. (2008). Managerial decisions: study guide set. Moscow: EOI Publishing Center, p. 14.

2. Chudnovskaya, S.N. (2007). Managerial decisions. Moscow: Eksmo, pp. 10-13.

3. Daft, R.L. (2009). Management. 8th ed. St. Petersburg: Piter. (Original work published 8).

4. Deming, W.E. (2000). The New Economics for Industry, Government, Education. $2^{\text {nd }}$ edition. Cambridge, Massachusetts, USA: The MIT Press.

5. Dettmer, W. (2013). Goldratt's Theory of Constraints: A Systems Approach to Continuous Improvement (Translated from English). Moscow: Alpina Publisher.

6. Drucker, P.F. (1964). Managing for Results. New York: Harper \& Row, p. 5.

7. Dulzon, A.A. (2009). Development of managerial decisions. Tomsk: Publishing house of Tomsk Polytechnic University, p. 60.

8. Fatkhutdinov, R.A. (2007). Managerial decisions. $6^{\text {th }}$ ed. Moscow: INFRA-M.

9. Fidelman, G. (2015). System management: How to start the Toyota way. Moscow: Alpina Publisher.

10. Filinov, N.B. (2009). Developing and taking managerial decisions: study guide. Moscow: INFRA-M (MBA textbooks). p. 10.

11. Firsova, I.A., Danilova, O.V. \& Karpov, C.V. (2012). Managerial decisions. Moscow: Yurayt.

12. Gaponenko, T.V. (2008). Managerial decisions. Rostov-on-Don: Fenix.

13. Hahn, D. (1997). Planning and control: the concept of controlling (Translated from Germ). Moscow: Finance and Statistics, pp. 29-30.

14. Hammond, J.S., Keeney, R.L. \& Raiffa, H. (2007). Smart Choices: A Practical Guide to Making Better Decisions (Translated from English). Novosibirsk: Sib. Univ. Publishing house, p. 21, p. 187.

15. Horvath, V. et al. (2005). Concept of controlling: Managerial accounting. Reporting system. Budgeting. Moscow: Alpina Business Books, p. 19. 
16. Kulagin, O.A. (2001). Decision-making in organizations. St. Petersburg: Publishing House "Sentiabr", p. 7.

17. Liker, J. (2014). The Toyota Way. Moscow: Alpina Publisher.

18. Litvak, B.G. (2012). Managerial decisions. Moscow: Moscow Financial-Industrial Academy, p. 41, pp. $343-344$.

19. Mescon, M.H., Albert, M. \& Khedouri, F. (2002). Management (transl. from English). Moscow: Business, p. 195.

20. Mullakhmetov, K.S. (2005). Some approaches to management control, Management in Russia and abroad, 6, pp. 3-9.

21. Mullakhmetov, K.S. (2011a). Modern approaches and concepts in the practice of business management, Management in Russia and abroad, 6, pp. 76-82.

22. Mullakhmetov, K.S. (2011b). The process approach to the organization of control in Russian companies, Economics and Management, 8, pp. 53-57.

23. Mullakhmetov, K.S. (2013). Control Management. Moscow: Economics, p. 161.

24. Mullakhmetov, K.S. (2015). Some approaches to the development of the management control concept, Journal of Advanced Research in Law and Economics, 6 (1), pp. 128-137. Available at: doi:10.14505/jarle.v6.1(11).15.

25. Mullakhmetov, K.S., Aminova, R.M. \& Akhmetshin, E.M. (2014). Control in a management system in modern conditions, Asian Social Science, 10 (24), pp. 237-247. Available at: doi:10.5539/ass.v10n24p237.

26. Raizberg, B.A., Lozovsky, L.Sh. \& Starodubtseva, E.B. (2007). Modern economic dictionary. Moscow: INFRA-M.

27. Robbins, S.P. \& Coulter, M. (2004). Management. $6^{\text {th }}$ ed. Moscow: "Williams" Publishing House.

28. Ryzhenkova, I.K. (2011). Manager's skills: Improving personal and team commitment. Moscow: Eksmo.

29. Shegda, A.V. (1998). Fundamentals of management: study guide. Kyiv: Association “Znanie”, KOO, p. 296.

30. Smirnov, E.A. (2002). Development of managerial decisions: textbook for universities. Moscow: UNITY, p. 63.

31. Woodcock, M. \& Francis, D. (1991). The Unblocked Manager. For a practical manager (Translated from English). Moscow: Business. 